| ARTÍCULO

\title{
Utopía, derecho y moral en Mi lucha de K. O. Knausgård ${ }^{1}$
}

\section{Utopia, Law and Morality in My Struggle by K. 0. Knausgård}

\author{
Lucas E. Misseri \\ Departamento de Filosofía del Derecho y Derecho Internacional Privado \\ Facultad de Derecho \\ Universidad de Alicante
}

Fecha de recepción 25/11/2019| De aceptación: 06/04/2020 | De publicación: 15/06/2020

\section{RESUMEN}

La novela autobiográfica de Knausgård es un caso paradigmático para el análisis del vínculo entre derecho y literatura, porque permite tener tres perspectivas del mismo: la del derecho en, de y como literatura. En este artículo se hace hincapié en la primera. La tesis que se defiende es que la problemática postura de Knausgård de hablar de "utopía nazi" es comprensible si se la compara con los problemas de hablar de un derecho nazi. Siendo el aspecto más criticable el relativismo moral que sustenta dicha concepción, que le impide tener una visión más cabal del elemento justificativo de las utopías y del derecho.

\section{PALABRAS CLAVE}

Derecho y literatura, Derecho nazi, Utopismo, Relativismo moral.

\section{ABSTRACT}

Knausgård's autobiographical novel is a paradigmatic case for the analysis of the link between law and literature, because it allows us to have three perspectives of it: that of law in, of, and as literature. This article emphasizes the first one. The claim defended is that Knausgård's problematic position of speaking about a "Nazi utopia" is understandable when compared to the problems of speaking about a Nazi law. The most critical aspect of his conception is moral relativism, which prevents him from having a more complete view of the justifying element of utopias and law.

\section{KEY WORDS}

Law and Literature, Nazi Law, Utopianism, Moral Relativism

\footnotetext{
${ }^{1}$ Agradezco a J. J. Garza, A. Bugajska, G. Lariguet, D. J. Cevallos, I. Lifante y M. Atienza por la lectura de distintas versiones de este trabajo y por sus valiosos comentarios críticos.
} 
Sumario: 1. Introducción: derecho y literatura. 2. El problema de una "utopía" nazi: una analogía con el derecho nazi. 3. Knausgård, el relativismo y la contemporaneidad. 4. Conclusión. Bibliografía.

\section{Introducción: derecho y literatura}

"Derecho y literatura" es considerado un movimiento interdisciplinar que tomó fuerza entre académicos estadounidenses en las décadas de 1970 y 1980. Puede citarse como ejemplo de dicho movimiento el libro The Legal Imagination de John Boyd White ([1973] 1985), texto que buscaba contribuir a la formación de futuros abogados por medio del análisis de piezas literarias. No obstante, hay buenas razones para considerar que el derecho y la literatura tienen un vínculo fuerte desde el nacimiento de la escritura. Esto, por un lado, porque el derecho -en tanto que dependiente de la transmisión lingüística de sentidos - conforma un corpus de letras con ciertos fines que privilegian ciertos tipos de interpretaciones y, por el otro, porque el derecho como fenómeno cultural está presente en otros ámbitos literarios, especialmente en aquellos narrativos, ya sean de tipo ficcional o no.

El caso que se aborda en este artículo es un caso límite, puesto que se trata de una autobiografía que no está ajena a cierto grado de ficción. En la hexalogía que conforma Mi lucha del autor noruego Karl Ove Knausgård, se describe su vida y, en especial, el duelo por la muerte de su padre. En español los seis volúmenes llevan los siguientes títulos: 1) La muerte del padre, 2) Un hombre enamorado, 3) La isla de la infancia, 4) Bailando en la oscuridad, 5) Tiene que llover y 6) Fin y, como puede inferirse por los títulos, el orden no es estrictamente cronológico. Esta obra de Knausgård tiene un interés múltiple para los estudios literarios: Primero, por su condición de texto premiado por la crítica literaria contemporánea, especialmente la escandinava aunque no sólo por ella. Segundo, por la particularidad de ser la novela más extensa de la literatura noruega, además de un ejemplo de tensión entre autobiografía y autoficción ${ }^{2}$. Sin embargo, Mi lucha es interesante para el estudioso del derecho, no tanto por esas características, sino porque pone en juego diversos vínculos de la relación derecho y literatura.

\footnotetext{
${ }^{2}$ Hay que reconocer que es difícil delimitar entre la autobiografía y la autoficción, se trata más bien de una cuestión de grado. No obstante, las continuas referencias de Knausgård a su intención de dar una visión real de su vida traen a colación en el contexto literario la paradoja de Epiménides. Esto porque, tanto si la intención del autor es decir la verdad como mentir, en ambos casos se mostraría explícitamente a favor de decir la verdad.
} 
Desde los estudios de derecho y literatura se han identificado varias formas de pensar la relación de ambos ámbitos. Una de las clasificaciones más difundidas es la propuesta por el jurista belga François Ost (2017, 22), quien divide los estudios sobre dicho vínculo en cuatro corrientes bien diferenciadas. Primero, el enfoque del derecho de la literatura, es decir, las regulaciones en torno, por un lado, al derecho de autor y, por el otro, a la libertad de expresión. Las tensiones en las que entra Mi lucha con esas dimensiones del derecho ya se pueden evidenciar desde el título elegido por Knausgård. El mismo hace referencia explícita al libro homónimo que Adolf Hitler publicó en 1924, libro que estuvo prohibido para su publicación y distribución en muchos países después de la Segunda Guerra Mundial ${ }^{3}$. Asimismo, otro aspecto que manifiesta el conflicto entre derechos surge a partir de la decisión de Karl Ove Knausgård de publicar testimonios de su propia vida y de su entorno con los nombres y apellidos reales de los involucrados. Esto condujo a un proceso judicial por parte de su tío que fue a la par de que se publicasen los seis volúmenes. Su tío adujo que se estaba atentando contra la reputación del apellido Knausgård ${ }^{4}$. Por ello, Karl Ove Knausgård se vio forzado a modificar varios pasajes de su voluminoso escrito y, al mismo tiempo, se vio motivado a tematizar dicho problema en gran parte de la novela. Esto sin contar que su proceso creativo estuvo mediado por asesores jurídicos encargados de leer cada volumen antes de su publicación y sugerirle modificaciones. Ese conflicto manifiesto entre la libertad de expresión y el derecho al honor de sus allegados hace que Mi lucha sea un caso interesante para su estudio.

En segundo lugar, existe otro enfoque posible que es el del derecho en la literatura, es decir, los conceptos jurídicos e ideas afines a la cultura jurídica que aparecen expuestos de modo manifiesto o implícito en obras literarias. Casos paradigmáticos estudiados por este enfoque son Antígona de Sófocles, El mercader de Venecia de Shakespeare, Michael Kohlhaas de Von Kleist, El proceso de Kafka, Resurrección de Tólstoi, etc. Desde este punto de vista, Mi lucha de Knausgård tiene interés porque pone en juego temas como la distinción entre la libertad de creación y la regulación jurídica sobre la base de la creencia defendida por Ost de que "...la literatura libera posibles, el derecho codifica la realidad..." $(2017,36)$. Pero, lo que puntualmente interesa en este artículo es la visión general sobre el rol del derecho y la moral en las sociedades contemporáneas, a partir de una concepción muy especial de utopía que se

\footnotetext{
${ }^{3}$ Sobre la historia de Mi lucha de Hitler en general, los datos cuestionables de su autobiografía y las prohibiciones y ediciones clandestinas del libro en especial véase Kellerhof (2016).

${ }^{4}$ Para una discusión sobre la importancia de tratar temas políticos con nombre y apellido real de los participantes y cuándo razones prudenciales demandarían la anonimización de alguno de los involucrados véase Lariguet (2019).
} 
sigue de lo escrito por Knausgård en el último volumen de su obra Fin: Mi lucha 6. Si como dice Ost, la literatura libera "utopías creadoras" (ibid.), entonces estas se vuelven especialmente relevantes para el derecho cuando pueden afectar las conductas y motivaciones de los individuos, yendo más allá de la mera experiencia estética.

En tercer lugar, Ost $(2017,28)$ reconoce un enfoque del derecho como literatura. Este enfoque aborda el derecho desde las técnicas asociadas a la interpretación literaria y los puentes que pueden trazarse con la crítica literaria en general. En este marco hay problemas atractivos como aquellos que atañen al rol del autor y el parangón con el rol del legislador. Knausgård apenas trata este tema en su libro, por lo cual no es tan relevante este abordaje para este artículo. El noruego se limita a hacer una comparación entre el rol del editor y el rol del asesor jurídico en la lectura de sus manuscritos y cómo ambos trabajan con el lenguaje, pero con finalidades distintas. No obstante, hay estudios valiosos sobre el tema en Ronald Dworkin, como cuando el iusfilósofo aborda en qué modo el derecho se asemeja a la literatura $(1985,146)$ o en su metáfora de la novela en cadena ([1986]1992, 166). También puede mencionarse el análisis del vínculo entre el rol del juez y la educación emocional en la obra de Martha Nussbaum (1997). O el problema de la intencionalidad del autor en Enrique Marí (1998) e, incluso, en un crítico del movimiento derecho y literatura como es Richard Posner (2009). En el contexto hispanohablante un ejemplo notable por aumentar los estudios de derecho y literatura lo constituye José Calvo González: con respecto a este enfoque derecho como literatura puede citarse su trabajo sobre el derecho constitucional estadounidense desde una perspectiva teórico-literaria (2010) y sobre todos los enfoques en general, su reciente obra dedicada a las distintas dimensiones de la cultura literaria del derecho (2018).

Finalmente, en sus trabajos más recientes Ost distingue un cuarto enfoque que denomina el derecho por la literatura y lo define como aquél en el que un jurista populariza ciertos temas jurídicos por medio de la literatura. Además de su propio libro de cuentos jurídicos (Ost 2019) se pueden mencionar casos notables recientes como el del jurista alemán Ferdinand von Schirach (2011), entre otros. Este enfoque no es aplicable a Knausgård porque no es un jurista, ni su obra parece perseguir una finalidad jurídica. 
Una vez hechas estas aclaraciones con respecto al estado del arte del área de estudios del derecho y la literatura, se explicita que el enfoque preferido aquí es el del derecho en la literatura y las tesis a defender son las siguientes:

1. Leer Mi lucha en clave de "derecho en la literatura" puede enriquecer nuestra comprensión del derecho como fenómeno social, incluso aunque la finalidad de Knausgård sea estética, comercial y/o existencial.

2. Por medio de la explicitación de la concepción de la utopía y la moral que expone Knausgård, especialmente en su último volumen, puede reconstruirse una visión iusfilosófica particular.

3. La visión iusfilosófica subyacente en Knausgård es positivista-relativista y es dicho relativismo el que lo lleva a afirmaciones filo-fascistas.

Se espera que el trabajo que sigue sea una muestra de la primera de estas tesis, la misma será mantenida como un presupuesto metodológico del enfoque derecho y literatura y no será discutida en este trabajo. En cuanto a las tesis segunda y tercera, éstas serán tratadas en las correspondientes secciones: En la sección segunda se abordará la analogía entre la utopía nazi y el derecho nazi, el presupuesto es que la utopía es el tipo ideal de sociedad que mejor se adecua a las visiones sociales complejas en las que se enmarcan las principales perspectivas iusfilosóficas ${ }^{5}$. Finalmente, en la sección tercera, se subrayará el elemento relativista como la mejor explicación a la concepción desigualitaria de la utopía presente en Mi lucha de Knausgård y, en especial, en su sexto volumen, Fin, y cómo ésta pone en juego una visión no sólo limitada del derecho sino también peligrosa.

\section{El problema de una "utopía" nazi: una analogía con el derecho nazi}

En el último volumen de Mi lucha, el autor noruego incluye un ensayo de unas cuatrocientas páginas. En él, Knausgård defiende varias tesis controvertidas que podrían resumirse en dos afirmaciones centrales interrelacionadas. Dichas afirmaciones ponen en juego aspectos valorativo-normativos como son la noción de utopía y una visión sobre la moral y el derecho. La primera podría ser llamada "tesis del

\footnotetext{
${ }^{5}$ Para una defensa de este presupuesto véase J. C. Davis (1985), M. A. Ramiro Avilés (2002), Martínez Roldán (2007) y Misseri (2019).
} 
carácter no excepcional de la figura de Adolf Hitler”. En otras palabras, Knausgård sostiene que la maldad de Hitler no es excepcional, sino que se explica por la mentalidad europea de la primera mitad del siglo XX. Para ello ofrece varios ejemplos de la época y de la cultura germana en general. La segunda tesis, que podría ser llamada tesis del utopismo amoral, sostiene que el nazismo constituye el último movimiento político utópico, en tanto que fue la última defensa organizada a gran escala de lo local frente a lo universal.

Para exponer la primera tesis Knausgård va construyendo su voz autobiográfica en Fin: Mi lucha 6 pintándola con matices desigualitarios, incluso casi abiertamente racistas. La construcción gradual de su yo-personaje de Mi lucha (Min Kamp en noruego) entra en espejo con el Hitler-autor de Mi lucha (Mein Kampf). Por ejemplo, antes de iniciar el ensayo sobre el líder nazi, el noruego dice de sí mismo: “...yo estaba en contra de la inmigración, en contra del multiculturalismo, en contra de casi toda clase de ideas de igualdad" (Knausgård 2019, 74). En otro momento, se refiere a un grupo de italianos mayores de edad, reunidos en una pizzería sueca, como "mafiosos" por sus "ojos malvados" (p. 95). Tampoco duda en decirle a su hija que un mendigo: "Seguramente procede de Europa del Este. Son unos países muy lejanos. Vienen aquí a pedir dinero. Forman una especie de pandilla” (p. 99). No queda claro si es que Knausgård intenta mostrar que Hitler no era el monstruo que uno esperaría o más bien que él, e incluso quizá el lector de su obra, tiene también algo de monstruoso en sus pensamientos cotidianos. En otras palabras, Knausgård no necesita mostrar que Hitler no era malvado, le basta con mostrar lo malvado en nosotros para probar el carácter no excepcional de la maldad de Hitler. Para hacer esto se vale de varios testimonios de la época, que tenían el mismo ánimo belicoso que el futuro Führer o que despreciaban a los judíos ${ }^{6}$. En palabras del autor noruego:

A un individuo como Hitler, que fue oprimido, a quien su padre pegaba, que perdió a sus hermanos y a su madre, que se hizo adulto en una sociedad cuyos enormes cambios desencadenaron fuerzas que presionaron las estructuras y poco a poco las hicieron desmoronarse, que vivió la matanza en masa durante la Primera Guerra Mundial y la siguiente turbulencia social rodeado de violencia, a una persona como él la conciencia no le «decía» lo mismo que nos dice a

\footnotetext{
${ }^{6}$ El autor noruego cita incluso a Kafka como ejemplo de autodesprecio por su condición de judío y como caso paradigmático del rol del contexto en el reproche moral del discurso (Knausgård, 2019, p. 669).
} 
nosotros, que no hemos vivido nada de eso. Pero se lo dijo a otros de su generación, porque ninguna de las experiencias vividas por Hitler fueron solo suyas ni nada de lo que escribió en $M i$ lucha era inaudito, es decir, todo lo que hay en Mi lucha también existe en otros lugares de la sociedad de aquella época. (Knausgård 2019, 672)

Esta idea de un Zeitgeist desigualitario es la fundamentación de la primera tesis del autor ${ }^{7}$. Antes de indagar en sus debilidades es necesario explicar cómo justifica la segunda, la tesis del utopismo amoral. Todo el volumen Fin: Mi lucha 6 es el que tiene más elementos autorreferentes a la obra en su conjunto y el que contiene el ensayo sobre Hitler que justifica el título de los seis tomos. En todo este sexto volumen se da una dicotomía entre dos planos que están entrelazados por un juego dialéctico entre, por un lado, lo individual, la utopía como defensa de lo local y la autobiografía como narración de lo real frente, por otro lado, a lo social, lo moral y lo jurídico como un conjunto de limitaciones convencionales de los primeros y, por tanto, más artificiales e irreales que aquellos. Knausgård dice que tiene que contar la verdad sobre su vida y eso implica entrar en conflicto con el plano social, por eso se compara con Hitler y por eso intenta ver los aspectos en común entre la defensa de lo local que hizo el líder germano y su propia defensa de una subjetividad descripta sin limitaciones sociales, ya sean morales como jurídicas. Para Hitler lo local era lo alemán, lo ario, el partido nacionalsocialista; para Knausgård son las emociones, políticamente incorrectas de acuerdo a estándares igualitaristas, que le generan las interacciones con los miembros de su comunidad: ya sean su padre, su mujer, sus hijos, su tío, sus vecinos, etc.

Al detenerse en esta segunda tesis, puede observarse que lo que intenta hacer Knausgård es separar la moralidad de la literatura y eso le lleva a defender a autores como su compatriota Knut Hamsun y al austríaco Peter Handke sobre la base de su estilo literario ${ }^{8}$. Ambos novelistas no dudaron en elogiar a personajes moralmente cuestionables como Hitler, en el primer caso, y Slobodan Milosevic, en el

\footnotetext{
${ }^{7}$ Esta tesis es en parte avalada por Rüthers (2016) en su intento de explicación de por qué ocurrió la degeneración del derecho alemán entre 1933 y 1945 cuando afirma que "También los jueces están sometidos al espíritu de la época e influidos por él” (p. 227) y el rol que juegan los valores de la sociedad en la determinación del derecho en una época y lugar particulares.

${ }^{8}$ Mientras escribo estas páginas a Handke se le ha concedido el premio Nobel de Literatura por su "ingenio literario", lo que parece darle la razón en parte a Knausgård y a quienes bregan por la separación entre lo literario y lo político. No obstante, el caso del autor de Mi lucha no es exactamente igual al del austríaco porque no se trata tanto de cuestión de estilo únicamente sino de la difusión pública de detalles íntimos de su entorno familiar conservando los nombres originales. Mientras que en el caso de Handke el conflicto viene por el contraste entre su obra y su vida pública. En Knausgård, la distinción entre obra y vida pública y privada no es tan fácil de trazar.
} 
segundo. Como se dijo más arriba, el parangón que puede trazarse entre Knausgård y Hitler es su defensa de lo local, lo propio, al margen de la moral universalista e igualitarista que caracteriza, por ejemplo, a gran parte del discurso en torno a los derechos humanos. Esto le lleva a decir cosas como que:

El nazismo fue el último gran movimiento político utópico que ha existido, y el que resultara destructivo en casi todos los sentidos ha hecho que todo pensamiento utópico posterior sea problemático, por no decir imposible, no solo en la política, sino también en el arte, y como el arte en su esencia es utópico, desde entonces está en crisis, es decir, siempre está haciendo examen de conciencia, siempre resulta sospechoso, algo que muestra la novela de Handke y casi todas las novelas escritas por autores de su generación. ¿Cómo representar la realidad sin conferirle algo que no tiene? (Knausgård 2019, 154)

"Utopía" es un término polisémico y, por tanto, es difícil llegar a acuerdos en torno a qué se quiere decir cuando se lo usa en un contexto determinado. No obstante, pueden distinguirse tres elementos relativamente claros en gran parte de lo que se refiere académicamente como una utopía: un elemento simbólico-ficcional, un elemento teórico-justificativo y un elemento práctico-aplicativo ${ }^{9}$. Reconocidos estos elementos, que tienden a tener distinto énfasis - lo que permite hacer tipologías de las utopíascabe hacerse la pregunta: ¿puede hablarse de una "utopía” nazi? Este es un problema que algunos autores han abordado y han dado diversas respuestas. Una respuesta frecuente es la negación de la posibilidad de una utopía nazi por incumplir el elemento teórico-justificativo. Ya sea por no producir un extrañamiento emancipador (Suvin 1979) o por la contraposición entre mito/totalitarismo ${ }^{10}$ y utopía/emancipación en el caso de Miguel Abensour, para quien la "idea misma de una utopía nazi es una idiotez. No sólo la utopía no es la cuna del totalitarismo sino que éste se eleva sobre el cadáver de la utopía" (en Hernández 2010, 49). Otra respuesta es la de quienes aceptan la posibilidad de hablar de utopía nazi, ya sea porque lo ven como una deriva del perfeccionismo que caracteriza al utopismo en

\footnotetext{
${ }^{9}$ Para clasificaciones tripartitas de la utopía véase por caso la obra del politólogo estadounidense L. T. Sargent (1994), en la que distingue entre utopía literaria, comunidad utópica y teoría social utópica o la del filólogo y filósofo rumano C. Braga (2018) que distingue entre utopías literarias, teóricas y prácticas.

${ }^{10}$ No hay acuerdo generalizado sobre la distinción mito/utopía. Por ejemplo, mientras autores como G. Bueno (2006, 16) ven una línea de continuidad entre mito y utopía, B. Baczko (1999, 89-104) los presenta como conceptos diferentes pero complementarios. Las limitaciones de extensión no permiten abordar el problema de esta distinción, pero la tesis que se defiende es que si bien el mito tiene carácter simbólicoexplicativo la utopía tiene un carácter simbólico-justificativo.
} 
general (Popper [1945]1985; Gray 2008 ${ }^{11}$ ) o porque es algo que caracteriza a algunas utopías en particular, pero sin por eso considerarlo un elemento necesario del utopismo (Sargisson 2012).

El problema radica en que en una utopía hay un elemento valorativo muy importante -la deseabilidad - que incluso permite, en algunos casos, hacer la distinción entre utopías y distopías ${ }^{12}$. Desde la perspectiva del siglo XXI parece relativamente sencillo afirmar que el programa nazi fue una distopía realizada. Pero es más difícil sostener que fuese una utopía -en sentido positivo- porque, incluso aun cuando el belicismo y el antisemitismo no eran extraños en su época, el accionar nazi difícilmente fuera justificable en el grado de deshumanización que fue ganando desde las leyes racistas de 1933 al genocidio industrializado de los últimos años del régimen. Un problema afín se plantea con respecto al estatus jurídico del Estado nazi, ¿existió un derecho nazi? ¿Puede la fórmula de Radbruch explicar si el ordenamiento jurídico alemán pierde validez en casos de injusticia intolerable? ${ }^{13}$ Ambas cuestiones ponen el acento en hasta qué punto los programas políticos y las instituciones pueden (o no) estar ajenos a la dimensión valorativa. El caso alemán sirve de paradigma, pero obviamente no es el único caso en el que el derecho se degenera para cumplir fines ilegítimos. Una de las múltiples lecciones que, según el jurista alemán Bernd Rüthers, deja dicha dolorosa experiencia histórica es que:

"Los juristas han de reconocer como un asunto esencial de su oficio su relación con el sistema de valores subyacente al ordenamiento jurídico. No existe una jurisprudencia apolítica, ideológicamente neutral y éticamente libre de valores. Un derecho libre de valores sería literalmente un derecho sin-valor.” (Rüthers 2016, 231).

Es en este sentido en el que comparar los problemas que surgen en torno a si existió una utopía nazi con la pregunta sobre si existió un derecho nazi puede aportar algo de luz al problema. Algunos

\footnotetext{
${ }^{11}$ El caso de Gray no es exactamente igual al de Popper porque el primero acepta la legitimidad de las comunidades intencionales como se puede ver en este pasaje: "La búsqueda de la utopía no tiene por qué desembocar en totalitarismo. Mientras ese anhelo se circunscribe al ámbito de las comunidades voluntarias..." (Gray 2008, 60).

12 En ocasiones se habla de "utopía positiva" y "utopía negativa”, o de "eutopía" y "distopía”, o de utopía y "anti-utopía". Cada uno de esos términos no es exactamente equivalente y sus significados varían según cada autor. Aquí la distinción es entendida en su forma más básica según la cual una utopía es la visión de una sociedad imaginaria deseable y la distopía una forma indeseable. Para una problematización de las variables de deseabilidad y posibilidad de las utopías véase Fernández (2005).

${ }^{13}$ Sobre este tema véase la defensa de la fórmula de Radbruch en R. Alexy (2001) y la revisión de las posturas de Radbruch, Kelsen, Fuller y Hart sobre el derecho nazi que hace Pérez de la Fuente (2011) en el contexto del caso de los tiradores del Muro de Berlín, donde el Tribunal Constitucional Federal de Alemania empleó la fórmula radbruchiana en su versión que hace hincapié en la intolerabilidad (Unerträglichkeit) (Pérez de la Fuente 2011, 468).
} 
autores desde una perspectiva más bien formalista no dudaron en reconocer que el derecho, en tanto que conjunto de normas sancionadas por una autoridad competente y reconocidas en una comunidad dada podía ser inmoral, dado que la esfera valorativa no correspondía a lo jurídico en sentido estricto. Eso no implicaba que no pudieran hacerse juicios de valor sobre el mismo, pero la valoración no afectaba a la juridicidad. Un caso notable es el de H. L. A. Hart, que consideraba que entre una visión amplia del derecho que incluyese reglas válidas, aunque inmorales, y uno restringido, en el cual dichas reglas no tuvieran reconocimiento de juridicidad, había que adoptar la primera visión. Esto porque la segunda -la visión restringida - implica, por un lado, negarle juridicidad a reglas formalmente válidas y, por otro lado, ceder lo constitutivo de la juridicidad a otras disciplinas, lo que desde su perspectiva sólo podría traer confusión (Hart [1961]1998, 258-259). Temprano desacuerdo con esta postura había mostrado Lon L. Fuller, con quien Hart había iniciado una discusión en la Harvard Law Review durante $1958^{14}$. Así como Hart plasmó su postura en El concepto de derecho en 1961, Fuller hizo lo mismo en su libro La moralidad del derecho de 1964. En ambos casos, la fuente del debate entre ambos autores había sido, entre otras cosas, la situación de aquellos que se habían aprovechado de las leyes nazis. Se planteaban si en esos casos los sujetos debían ser juzgados por cumplir unas leyes injustas, si debía hacerse una ley retroactiva para condenarlos o, directamente, no reconocer su carácter de genuino derecho sobre la base de una moral interna al derecho que el nazismo había traspasado.

Otra línea no positivista, o pospositivista, que además de enfocarse en la perspectiva estructural del derecho incluye a la funcional y a la valorativa, es la de autores como Robert Alexy. Para el jurista alemán el derecho tiene una doble naturaleza: por un lado, tiene una dimensión real o fáctica -las reglas y su eficacia - y, por el otro, una dimensión ideal o crítica-los principios- El elemento ideal se conjuga alrededor de lo que Alexy llama la "pretensión de corrección”. Todo ordenamiento jurídico tiene una pretensión de corrección, no basta con el mero elemento autoritativo. Para defender esto Alexy ofrece ejemplos que intentan demostrar, por el absurdo, la necesidad de esa pretensión. Tal es el caso, por ejemplo, de una república que se considerase a sí misma manifiestamente injusta o el de una condena que asumiese explícitamente una interpretación errónea del derecho vigente (2016a, 27-28). Sin embargo, esto prima facie no parece suficiente para objetar el carácter jurídico del derecho nazi, porque

\footnotetext{
${ }^{14}$ Para una traducción al español de dicho intercambio véase Hart y Fuller (2016).
} 
sobre la base de la autoridad del Führer y de principios racistas pseudocientíficos también tenía una pretensión de corrección. Ahora bien, Alexy $(2016 b, 45)$ considera que la dimensión ideal del derecho puede ser subdividida en cinco elementos que él llama el "pentágono de la dimensión ideal": 1) la fórmula de Radbruch, como límite para lo jurídico, 2) la tesis del derecho como caso especial de los discursos prácticos, 3) su teoría de los principios, 4) una concepción deliberativista de la democracia y 5) la positivización de los derechos humanos en las constituciones, elemento que caracteriza a un buen número de constituciones posteriores a la Segunda Guerra Mundial. Si bien no hay consenso sobre estos temas, es cierto que muchas constituciones incluyen elementos explícitamente valorativos que van desde apelaciones a la dignidad e igualdad del ser humano que forzarían a interpretaciones muy sui generis para quienes quisieran soslayarlos. En otras palabras, para crear un régimen autoritario desigualitario estos elementos supondrían un fuerte obstáculo, pero como parece mostrar la experiencia histórica, no necesariamente lo haría imposible.

En resumen, parece al menos equívoco hablar de utopía nazi del mismo modo que, si se aceptan algunos presupuestos de las visiones pospositivistas, también parece extraño hablar de derecho nazi. Esto porque, en ambos casos, los fines perseguidos por ambos discursos normativos son difíciles de justificar bajo ciertos criterios de razonabilidad básicos como por ejemplo: la inclusión de los intereses de todos los afectados, la sinceridad y la aceptación del mejor argumento. Si en el caso del derecho se suele hablar de "derecho degenerado" (Rüthers 2016) para matizar el carácter no justificable de los fines perseguidos, en el caso de la utopía suele hablarse de "distopía" (Claeys 2017). En ambos casos queda expuesto el elemento valorativo que aquí se asume que forma parte de ambos, aunque en muchos casos este sólo aparezca implícito o sea solo una precondición. Si se quiere, en términos kantianos, cierto elemento valorativo justificable funciona como un trascendental en ambos contextos, es decir, es condición de posibilidad para hablar de utopía y de derecho.

\section{Knausgård, el relativismo y la contemporaneidad}

Para ir más allá de la analogía de la sección anterior vale aclarar que la pregunta que guía este artículo no es de tipo historiográfico, esto es, ¿por qué el pueblo alemán entre 1933 y 1945 avaló una visión tan injusta e inhumana de sociedad? Si no más bien, ¿por qué, hoy, un escritor noruego -dato no anecdótico, porque Noruega es uno de los países con mejores estándares de vida del mundo- considera 
que el nazismo fue un movimiento utópico? En principio, parecería que la postura de Knausgård se apoyase en el hecho de que el nazismo fue una construcción ficcional, sustentada a partir de símbolos, ideas y sentires de una sociedad golpeada por la Primera Guerra Mundial. La utopía de lo alemán "puro”, aunque fuese una ficción, fue una instancia para la movilización de todo un pueblo hacia una catástrofe, pero que, en sus primeras enunciaciones retóricas, tuvo una fuerza difícil de explicar y que radica en su aspecto simbólico. Algo que incluso reconoció un crítico de la utopía como Hans Jonas ([1979]1995) y que tiene que ver con el carácter movilizador de las utopías en tanto que imágenes de un estado de cosas social ideal. No obstante, parte de esa movilización se sustenta en el elemento teórico-justificativo de la utopía, es decir, que la misma debería estar moralmente justificada y es allí donde surgen aún más dudas al momento de defender la idea de usar el adjetivo "utópico" para calificar el movimiento político nazi.

Para Knausgård, quien parece proclive al relativismo moral, no hay tal cosa como una verdad moral universal y es en ese sentido en el que es tan válido hablar de la "utopía" racista del nazismo como de la utopía igualitarista de la Ilustración. Aún más, si se lee en detalle, el autor noruego considera más genuinamente utópico al nazismo que al igualitarismo. Esto porque su defensa de lo local está más cercana a lo que él considera la "verdad" de lo individual, que la igualdad ilustrada. Esto porque los ideales de la Ilustración, en su apología de la universalidad de ciertos valores, ocultaría la individualidad. Lo moral es visto como un añadido convencional que nada tiene que ver con la subjetividad. Lo moral es relativo a las sociedades, mutable, convencional. Hasta aquí su relativismo es de carácter descriptivo pero toma tintes metaéticos ${ }^{15}$ cuando dice que hay una verdad de lo individual y ella radica en aquello que nos horroriza del caso nazi: "Belleza exterior, carisma, heroísmo, violencia y muerte es lo no relativo, pertenecen a lo puro, lo no ambivalente, lo sencillo. Nuestra necesidad de verlo, de ver lo grandioso y lo que limita con lo absoluto es insaciable” (Knausgård 2019, 733-734). Mientras que las restricciones morales, y en el caso de su obra también las jurídicas, son ejemplos de intentos de añadirle a la obra de arte "algo que no tiene", puesto que: "La moral es el nosotros en el yo, es decir, una magnitud de lo social que está por encima de la verdad. El debe de la moral es la voz de la decencia, lo que nos salva. Pero

15 Para la distinción entre relativismo descriptivo (o cultural), normativo (o requerimiento moral) y metaético (los presupuestos ontoepistemológicos del relativismo) véase Carson y Moser (2001, 1-2). 
también es la voz de la limitación del yo, lo contrario de la verdad y de la libertad, lo que nos impide." (Knausgård, 2019, 722).

El caso de Knausgård es distinto por el hecho de que no se trata de un jurista, e incluso es un autor que niega explícitamente que la obra de arte deba tener valor teórico, aunque su ensayo sobre la poesía de Paul Celan en Fin parezca contradecirlo. De todos modos, la hexalogía de Mi lucha es valiosa porque atestigua hasta qué punto esa visión estrecha del derecho -como un conjunto de convenciones relativas a valores locales apoyados por la creencia en ellos de los funcionarios y otras autoridadessigue presente incluso en sociedades consideradas como más avanzadas. A la par que permite notar que no necesariamente es el componente formalista su elemento más peligroso sino el relativista.

Si la pregunta sobre si existe un derecho nazi se traduce a fin de cuentas en si la moral tiene incidencia en la juridicidad de un conjunto de normas, lo mismo puede pensarse para la pregunta por la utopía nazi. ¿La moral afecta al carácter utópico de un programa político? Como se adelantó, la respuesta parece llevar al campo de la metaética y al problema de si existe algo similar a una verdad moral. Esta parece una pregunta demasiado ambiciosa para este artículo, pero no obstante, quizá la salida más pragmática radique en sostener que hay una serie de aspectos que tienen que ver con nuestro ser sujetos valoradores. Hay una serie de consensos que se construyeron a partir del fenómeno nazi que intentan impedir que algo así vuelva ocurrir. Si bien ese consenso es un hecho histórico, no lo es exclusivamente por accidente. Como Knausgård, podemos estudiar los testimonios del período nazi y pensar que hubo un Zeitgeist de pauperización no sólo económica sino cultural alemana que permite entender por qué algunas personas pueden haber llegado a tales límites, pero eso no implica que esa comprensión se extienda al ámbito de la justificación moral.

Podríamos concluir esta sección afirmando que una utopía implica un proyecto de convivencia moralmente justificado que intenta mejorar la calidad de vida de aquellos involucrados. Se puede decir que en ese sentido hay un elemento utópico en el deseo nazi de mejora de unos estados germanos unidos y productivos, pero los medios empleados son injustificables moralmente. No sólo porque emplean como medio a su propio pueblo, sino porque en esa cosificación de los conciudadanos judíos, disidentes, homosexuales, comunistas, romaníes, enfermos, etc., hay una degradación de la subjetividad moral de los victimarios. Algo que ya había visto Platón en su diálogo Gorgias, cuando decía, por boca de 
Sócrates, que "cometer injusticia es peor que sufrirla" (1983, 473a). Es en este sentido que parece difícil justificar la idea de una utopía nazi, aunque tal vez si sólo se tuviese en cuenta el elemento simbólico podría decirse que se trata de una pseudo-utopía. Ahora bien, entonces ¿todas las utopías del pasado que hoy vemos como distopías son pseudo-utopías? La cuestión radica en si ese objetivo de mejora social se hace por medios moralmente mejores que los conocidos en la propia época o no. Por ejemplo, es difícil cuestionarle a Tomás Moro que incluyese a la esclavitud como castigo para quienes cometiesen crímenes en Utopía ${ }^{16}$, en vistas de que la alternativa del siglo XVI no era la reclusión, sino la pena de muerte.

No obstante, el relativista podría aducir que hay aún algo que no está justificado. ¿Cómo valorar qué es mejor y qué es peor con respecto a una época? Un criterio básico es el de la dignidad humana, entendido no sólo en su faceta de acuerdo al principio de autonomía tan caro a la tradición liberal de los derechos humanos, sino también un principio de suficiencia en términos de justicia distributiva ${ }^{17}$. La dignidad humana implica el reconocimiento del otro en tanto que sujeto capaz de ejercer valoraciones y, al mismo tiempo, como sujeto vulnerable que necesita una serie de recursos materiales mínimos (suficientes) para llevar a cabo una vida digna (Atienza 2017, 23). Sobre la base de esos dos conceptos básicos aún queda mucho para la diversidad de valores humana, propia de los distintos ambientes en los que nos desempeñamos, pero ofrece un mínimo común moral para planes de vida diversos en comunidad. En el ámbito institucional, el derecho, juega el rol de cristalización de ese mínimo común moral. Por lo cual desde el momento en que el derecho nazi atentó contra la dignidad humana de gran parte de su población dejó de ser tal, del mismo modo que esos fines no podían constituir ninguna utopía.

\section{Conclusión}

La obra de Knausgård tiene varios méritos. Uno de ellos tiene que ver con la resignificación del título de la obra de Hitler para siempre. De ahora en más Mi lucha referirá a dos obras de diversa índole. Como se ha tratado de mostrar en este artículo, la obra del noruego tiene potencial para el movimiento

\footnotetext{
16 "Los Utópicos no reducen a la esclavitud a los prisioneros de guerra -a menos de que sean agresores-, ni a los hijos de esclavos, ni, en general, a ninguno de los que en otras tierras son vendidos como tales, sino a aquellos cuyo crimen merece ese castigo y a los que fueron condenados a muerte en alguna ciudad extranjera..." (Moro [1516] 2011, 152).

${ }^{17}$ El suficientismo es una teoría de la justicia que considera que las desigualdades materiales son moralmente relevantes hasta un cierto umbral de suficiencia. Cumplido dicho umbral las desigualdades no necesariamente son moralmente relevantes. Para una discusión sobre formas de suficientismo débil y fuerte véase Casal (2016).
} 
derecho y literatura, en tanto que pone en juego en diverso grado tres de sus principales dimensiones de análisis.

Con respecto al derecho en la literatura, se ha considerado aquí que lo más valioso era intentar ahondar en el concepto de utopía, tal como aparece en Mi lucha y plantear por analogía algunos interrogantes que la filosofía del derecho ya había abordado. Si esta disciplina se había preguntado por el estatus del derecho nazi, aquí se ha hecho lo mismo con la aserción de Knausgård de que el nazismo fue la última utopía política. La conclusión a la que se ha arribado es que así como hay límite a lo que se puede llamar derecho, también lo hay para lo que se puede llamar utopía. En ambos casos esto tiene que ver con un ámbito normativo muy preciso y en especial con la justificación moral. El relativismo moral que parece guiar la reflexión del autor le priva de reconocer el valor de esa dimensión: si todo es relativo, da igual una utopía nazi como una utopía de igualdad que subyace a la moral universalista y a los sistemas jurídicos democráticos contemporáneos. Una hipótesis que puede ayudar a entender este equívoco del noruego es que confunde el mito con la utopía. El mito tiene un carácter simbólico como la utopía y explicativo, mientras que la utopía cuenta con el carácter simbólico también, pero con una dimensión justificativa del orden de lo moral. Es en ese sentido que su dicotomía entre lo individual, lo utópicolocal y lo autobiográfico frente a lo social, moral y jurídico es si no falsa muy inexacta, porque parte de nuestros ordenamientos tienen principios que contribuyen desde lo social a garantizar las libertades individuales. Una utopía que negase eso más que de una utopía retrógrada ${ }^{18}$ se trataría de una distopía. Muchas veces el imaginario, más de tipo mítico que genuinamente utópico, que justifica esas visiones surge del desconocimiento de aquello pasado, lejano o local que se idealiza.

En cuanto a los dos enfoques que aquí no se han abordado -el enfoque del derecho de la literatura y como literatura-, me gustaría hacer algunas observaciones y dejar algunas preguntas abiertas al debate. En lo concerniente a la dimensión del derecho de la literatura, Knausgård busca innovar y provocar, algo característico de la literatura en contraposición al derecho, según Ost (2017). Ahora bien, la pregunta sería ¿que sea posible escribir sobre cualquier cosa implica que deba publicarse sobre cualquier cosa? Los seis volúmenes de Mi lucha describen a todo el entorno del escritor. Si bien es

\footnotetext{
${ }^{18}$ Algo parecido a una utopía retrógrada podría ser las utopías de la nostalgia por el pasado que Bauman (2017) llama retrotopías y que define como "“"mundos ideales ubicados en un pasado perdido/robado/abandonado que, aun así, se ha resistido a morir...” (p. 14) y como "negación de la negación de la utopía" (p. 17).
} 
justificable el uso que hace de la figura de su padre muerto, es más difícil justificar el grado de exposición al que somete a sus hijos menores. En lo concerniente al derecho como literatura, es interesante que en uno de los pasajes de Fin, al recibir informes literarios de sus editores e informes jurídicos de sus abogados, Knausgård advierte el vínculo que existe entre ambas tareas. La comparación se hace sobre la base de que ambos trabajan con el lenguaje, pero en el caso del abogado este está limitado no sólo por el mundo sino por la jurisprudencia. El error de Knausgård creo que radica en creer que la literatura está sólo limitada por el mundo empírico. Ese límite puede valer para el contexto de creación pero no para el contexto de publicación. Knausgård puede escribir sobre lo que su mente le dicte y su mente está limitada por las experiencias del mundo empírico, pero también influyen de modo directo e indirecto los hechos sociales. Ya sea tanto en su reacción emocional frente a las limitaciones morales de los otros, como en el caso de los editores razones de tipo comercial, estético, político, etc. que llevan a apoyar o no la publicación de una obra.

Finalmente, se seleccionaron dos frases que juntas parecen dar cuenta de que el autor de Mi lucha intuye, entre sus contradicciones internas, las tesis aquí defendidas: "Hölderlin era poeta, y me imaginaba que para un poeta lo utópico era el mundo sin lenguaje. (...) En el mundo fuera del lenguaje únicamente se podía estar solo.” (Knausgård 2019, 316). "Una ley fuera del lenguaje resultaba tan inimaginable como un poema fuera del lenguaje. La ley y el poema estaban unidos, eran dos caras del mismo asunto." (Knausgård 2019, 754). El derecho y la utopía -ya sea en su faceta estética como política - no pueden estar ajenos a la inclusión del otro. Una literatura meramente egocéntrica es tan absurda como un derecho sólo para unos pocos. 


\section{Bibliografía}

ALEXY, R., "Una defensa de la fórmula de Radbruch", Anuario de Filosofia do Direito da Universidade da Coruña, 5, 2001, pp. 75-96. Disponible en: https://ruc.udc.es/dspace/handle/2183/2109

ALEXY, R. La doble naturaleza del Derecho, Madrid, Trotta, 2016a, 101 pp.

ALEXY, R. "La dimensión real e ideal del Derecho", Acto de investidura del grado de doctor honoris causa, Zaragoza, Universidad de Zaragoza, 2016b, pp. 39-50.

ATIENZA, M., "Sobre la dignidad en la Constitución Española de 1978”, Revista do Ministério Público (152), 2017, pp. 9-30. Disponible $\quad$ en: http://rmp.smmp.pt/wpcontent/uploads/2018/02/2.RMP_152_NET_Manuel_Atienza.pdf

BACZKO, B., Los imaginarios sociales: memorias y esperanzas colectivas, Buenos Aires, Nueva Visión, [1984] 1999, 199 pp.

BAUMAN, Z., Retrotopía. Barcelona, Paidós, 2017, 172 pp.

BRAGA, C., Pour une morphologie du genre utopique, París, Garnier, 2018, 735 pp.

BUENO, G., El mito de la izquierda: las izquierdas y la derecha, Barcelona, Ediciones B, 2006, 325 pp.

CALVO GONZÁLEZ, J. "Constitutional Law en clave de teoría literaria: una guía de campo para el estudio", Dikaiosyne: revista semestral de filosofía práctica, 25, 2010, pp. 7-18. Disponible en: https://dialnet.unirioja.es/servlet/articulo?codigo $=3739165$

CALVO GONZÁLEZ, J. La destreza de Judith: estudios de cultura literaria de derecho, Granada, Editorial Comares, 2018, 417 pp.

CARSON, T. L. y MOSER, P. K. (eds.), Moral Relativism: A Reader, Nueva York-Oxford, Oxford University Press, 2001, 337 pp.

CASAL, P., "Por qué la suficiencia no basta" en: Igualitarismo: una discusión necesaria, editado por J. Gallego y T. Bullemore, Santiago de Chile, Centro de Estudios Públicos, 2016, pp. 265-295.

CLAEYS, G. Dystopia: A Natural History: A Study of Modern Despotism, Its Antecedents and Its Literary Diffractions, Oxford, Oxford University Press, 2017, 556 pp.

DAVIS, J. C., Utopía y la sociedad ideal: estudio de la literatura utópica inglesa 1516-1700, México, Fondo de Cultura Económica, 1985, 398 pp.

DWORKIN, R., A Matter of Principle, Cambridge (Mass.) y Londres, Harvard University Press, 1985, 425 pp.

DWORKIN, R., El imperio de la justicia, Barcelona, Gedisa, [1986] 1992, 328 pp.

FERNÁNDEZ, G., Utopía: contribución al estudio del concepto. Mar del Plata, Ediciones Suárez, 2005, 209 pp.

GRAY, J., Misa negra: la religión apocalíptica y la muerte de la utopía, Barcelona, Paidós, 2008, 318 pp.

HART, H. L. A. y FULLER, L. L. El debate Hart-Fuller, Bogotá, Universidad Externado de Colombia, 2016, 166 pp.

HERNÁNDEZ, E., “Utopía y emancipación: entrevista con Miguel Abensour”, Minerva 15 (10), 2010, pp. 48-51.

JONAS, H., El principio de responsabilidad: ensayo de una ética para la civilización tecnológica, Barcelona, Herder, [1979] 1995, 398 pp.

KELLERHOF, S. F., Mi lucha: la historia del libro que marcó el siglo XX, Barcelona, Ed. Crítica, 2016. 
KNAUSGÅRD, K. O., Fin. Mi lucha: 6, Barcelona, Anagrama, 2019.

LARIGUET, G., Cuando los filósofos politicos se equivocan: un ensayo sobre el fantasma de Siracusa, Córdoba (Argentina), Editorial Brujas, 2019.

MARÍ, E. E., "Derecho y literatura. Algo de lo que sí se puede hablar en voz baja", Doxa: Cuadernos de Filosofía del Derecho, 21 (II), 1998, pp. 251-287. DOI: https://doi.org/10.14198/DOXA1998.21.2.20

MARTÍNEZ ROLDÁN, L., "Derecho versus utopía (ubi societas, ibi ius)", Anuario de Filosofia del Derecho, (XXIV), 2007, pp. 365-386. https://www.boe.es/publicaciones/anuarios_derecho/articulo.php?id=ANU-F-2007-10036500386

MISSERI, L. E. "Utopía y derecho: un argumento en favor del reconocimiento de su vínculo", Escritos, 27 (58), 2019, pp. 119-139. DOI: http://dx.doi.org/10.18566/escr.v27n58.a06

MORO, T., Utopía, Madrid, Círculo de Bellas Artes, [1516] 2011, 200 pp.

NUSSBAUM, M. C., Justicia poética: la imaginación literaria y la vida pública, Barcelona, Andrés Bello, 1997, $183 \mathrm{pp}$.

OST, F., "El reflejo del Derecho en la literatura", Doxa: Cuadernos de Filosofia del Derecho, 29, 2006, pp. 333348. DOI: https://doi.org/10.14198/DOXA2006.29.17

OST, F., "Derecho y literatura: en la frontera entre los imaginarios jurídico y literario", en Torres, O. E., coord., Derecho y literatura: el derecho en la literatura, México, Libitum, 2017, pp. 21-50.

OST, F., Si le droit m'était conté, París, Dalloz, 2019, 218 pp.

PÉREZ DE LA FUENTE, O., "El caso de los tiradores del muro de Berlín. A vuelta con algunos debates clásicos de la Filosofía del Derecho del siglo XX", Cuadernos electrónicos de Filosofía del Derecho, 23, 2011, pp. 453487. Disponible en: https://ojs.uv.es/index.php/CEFD/article/view/767

PLATÓN, Diálogos II: Gorgias, Ménexeno, Eutidemo, Menón, Crátilo. Gredos, Madrid, 1983, 461 pp.

POPPER, K. R., La sociedad abierta y sus enemigos, Barcelona, Orbis, [1945] 1985, 2 vol., 440 pp.

POSNER, R. (2009), Law and Literature: Third Edition, Cambridge (Mass.) y Londres, Harvard University Press, $570 \mathrm{pp}$.

RAMIRO AVILÉS, M. A., «La utopía de derecho», Anuario de Filosofía del Derecho, 19, 2002, pp. 431-460. Disponible en: https://dialnet.unirioja.es/servlet/articulo?codigo $=756906$

RÜTHERS, B., Derecho degenerado: teoría jurídica y juristas de cámara en el Tercer Reich, Madrid, Marcial Pons, 2016, 245 pp.

SARGENT, L. T., “The Three Faces of Utopianism Revisited”, Utopian Studies, 5 (1), 1994, pp. 1-37. Disponible en: https://www.jstor.org/stable/20719246.

SARGISSON, L., Fool's Gold? Utopianism in the Twenty-First Century, Nueva York, Palgrave Macmillan, 2012, $301 \mathrm{pp}$.

SUVIN, D., Metamorphosis of Science Fiction, New Haven-Londres, Yale University Press, 1979, 317 pp.

VON SCHIRACH, F., Crímenes, Barcelona, Salamandra, 2011, 192 pp.

WHITE, J. B., The Legal Imagination: Abridged Edition, Chicago y Londres, The University of Chicago Press, [1973] 1985, $302 \mathrm{pp}$. 